\title{
De la conceptualización de la evaluación a la toma de decisiones específicas en el aula
}

Ana Rosa Arceo Luna

\section{Introducción}

$\mathrm{L}$

os modelos educativos actuales expresan una coincidencia en la visión del docente como un promotor del proceso de aprendizaje, el cual guía las actividades y orienta a los estudiantes al desarrollo de conocimientos de diversa índole; sin embargo, esta labor queda inconclusa sin un proceso de retroalimentación sobre su eficiencia. Por ello, evaluar el aprendizaje ofrece un insumo objetivo, a fin de tomar decisiones en los procesos educativos en general.

Todo aprendizaje puede y debe ser evaluado, aunque no sería funcional utilizar los mismos parámetros, criterios o instrumentos para todos los contenidos. La presente reflexión, inicialmente, muestra términos generales sobre evaluación de aprendizajes desde la acción del profesor, para posteriormente proponer una metodología que comprenda la necesidad de realizar evaluaciones pertinentes al curriculum, estudiantes y docentes.

\section{Del concepto de evaluación}

La noción de evaluación se define como "el juicio de valor que resulta de contrastar el resultado de la medición de una realidad empírica con un parámetro previamente definido" (Instituto Nacional para la Evaluación de la Educación, 2006; citado en Martínez Rizo, 2012: 22). Desde esta concepción, evaluar es un proceso integrador que comprende una serie de pasos concretizados en acciones esenciales; es decir, realizar una medición con un parámetro determinado y emitir un juicio de valor, añadiendo una consecuencia intrínseca: tomar decisiones.

Medir es la acción de valorar con criterios previamente establecidos el grado en que los objetivos planteados se han cumplido. Como una acción comparativa, se realiza mediante una recogida de información sistemática que permita observar de forma objetiva los aprendizajes desarrollados en contraste con aquellos esperados. No sólo los criterios de comparación son planificados, sino también la forma en que éstos son recuperados.

Los resultados de la medición sirven como referencia para ejercer un juicio de valor, consistente en la interpretación reflexiva de la información obtenida. Previo a tomar una decisión sobre los procesos de enseñanza, se establece una estimación donde se determine el aprendizaje logrado por los estudiantes, así como aquellos elementos que no han desarrollado, o no han prosperado de forma adecuada. Con los resultados de la medición es posible observar la metodología de enseñanza, el profesor puede de la medición sirven como referencia para ejercer un juicio de valor, consistente

en la interpretación reflexiva de la información obtenida. \〉 
analizar si las estrategias, recursos y elementos curriculares, hasta el momento, son significativos para los estudiantes; es decir, si tienen relevancia en una situación (Díaz, 2006).

Finalmente, los dos pasos anteriores sirven como insumo para tomar decisiones que conduzcan, por un lado, a comprender cómo se ha desarrollado el aprendizaje en los estudiantes y reconocer aquello que ellos mismos pudieran mejorar, identificando acciones para mantener o modificar. Por otro lado, estos pasos ayudan a valorar la labor docente, el aprendizaje logrado por los alumnos es el parámetro para comprender la pertinencia en las metodologías empleadas, contribuyendo a la evaluación del profesor.

La evaluación, si bien funge como un fundamento para la asignación de calificaciones que representen el aprendizaje obtenido por los alum- nos, ofrece mayores bondades en la labor educativa, pues aunque la asignación de calificaciones sea el fin más próximo considerado por muchos estudiantes, en el caso de los docentes comprende una evidencia concisa para mejorar su labor y contribuir a las adaptaciones propias de cada grupo de alumnos.

La acción de evaluar en torno al aprendizaje ofrece información sobre los procesos educativos, llevando como fin último la toma de decisiones que desde el aula conduzcan a una educación cada vez más para la vida y menos para los números; por ello cada disciplina, por sus características propias, propone contenidos diferentes y en consecuencia exige una evaluación adecuada a los mismos, sin discrepar de los elementos ya mencionados.

\section{《 El aprendizaje logrado por los alumnos es el parámetro para comprender la pertinencia en las metodologías empleadas, contribuyendo a la evaluación del profesor. $\gg$}
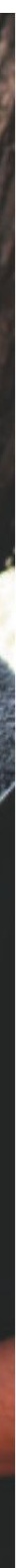


\section{Una metodología de evaluación para tomar decisiones específicas}

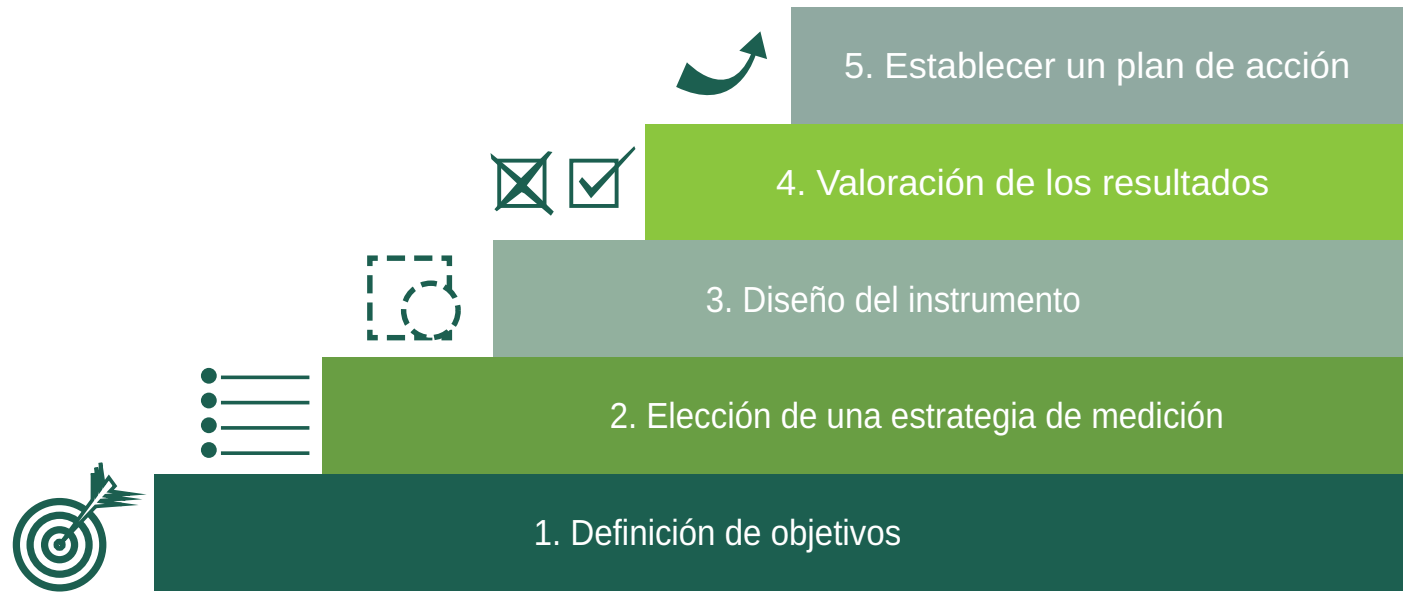

《 Evaluar concierne al desarrollo de

una metodología atenta a los distintos

contenidos, y que conduzca a tomar decisiones sobre las mejoras educativas. 》

\section{Una metodología de evaluación para tomar decisiones especificas}

Evaluar, en sus distintos momentos (al inicio del curso, al final, de forma intermedia o parcial y continua), más allá de la aplicación de una prueba prediseñada, concierne al desarrollo de una metodología atenta a los distintos contenidos, y que conduzca a tomar decisiones sobre las mejoras educativas.

Aquí una serie de pasos útiles, particularmente en el intermedio de un curso, para evaluar el aprendizaje:

1. Definición de objetivos: los programas de materia o carta descriptiva (según la denominación de algunas instituciones), muestran un objetivo general que brinda parámetros claros de lo que se pretende desarrollar en los contenidos, y plantean el tipo de parámetro que se utilizará según el contenido:

- Procedimentales: comprenden acciones orientadas a la consecución de una meta como son los hábitos, habilidades, estrategias, logaritmos, métodos, técnicas, entre otras. Ejemplo de redacción de estos contenidos: el estudiante diseñará, desarrollará, explicará, etcétera.
Esquema elaborado por el Departamento de Formación y Actualización Académica a partir del artículo "De la conceptualización de la evaluación a la toma de decisiones específicas en el aula", de Ana Rosa Arceo Luna.

- Conceptuales: abarca aquellos datos, hechos y conceptos, de los cuales se evaluará su comprensión y nivel de análisis.

- Actitudinales: engloba las cualidades de la personalidad desarrolladas para responder a determinadas circunstancias (López, Hinojosa, 2001).

Al determinar estos contenidos, es posible establecer en consecuencia el objetivo de la prueba.

2. Elección de la estrategia de medición: encontrar una estrategia o instrumento integrador que permita observar los procesos de aprendizaje de forma integral será siempre una decisión complicada. Clarificar aquello que se desea evaluar será el punto de partida, es decir, hacer presente el objetivo.

Quizá el instrumento empleado con mayor frecuencia son las pruebas escritas. Con un diseño adecuado a los contenidos que se desean evaluar, resulta un instrumento favorable; sin embargo, al realizar el discernimiento de la estrategia para evaluar, también deben considerarse otras técnicas cuya finalidad sea evaluar el desempeño, como son los portafolios, la solución de problemas, la elabo- 
ración de proyectos, las propuestas específicas, el debate, entre otras. Las estrategias que tiene la evaluación del desempeño plasman con mayor claridad los aprendizajes contextualizados, estableciendo así congruencia entre lo que se enseña y lo que se evalúa (Díaz, 2006).

3. Diseño del instrumento: deben establecerse los indicadores claros de los aprendizajes que se evalúan, mediante la pregunta, ¿qué elementos pueden mostrarme que tal o cual aprendizaje se ha desarrollado satisfactoriamente?, dependiendo de la estrategia, puede ser de utilidad diseñar una lista de cotejo, rúbrica o guía de observación, particularmente cuando la estrategia a emplear valorará el desempeño. Posteriormente, se procede a estructurar el o los instrumentos. En este punto, conviene considerar tres elementos centrales para la estructura:

- Adecuada para los objetivos planteados, es decir, que permita valorar lo enseñado, respondiendo a los objetivos definidos en el diseño, sin confusiones ni excesos.

- Accesible para los estudiantes, de forma que permita comprender con facilidad el procedimiento a seguir, y todos tengan posibilidades similares de participar en la estrategia de evaluación.

- Asequible para el docente, permitiendo una sencilla revisión y comprensión de los resultados, plasmando así no sólo los aprendizajes logrados, sino también los procesos inconclusos y los logrados satisfactoriamente.

Luego del diseño, se procede a la ejecución de la estrategia con particular atención en las especificaciones que conlleva.

4. Valoración de los resultados: en vano resultaría el proceso seguido sin el adecuado juicio de valor. Se sugiere observar los resultados obtenidos en la medición, además de integrar las observaciones cotidianas del aula que expresan en valores cualitativos los aprendizajes y establecer las preguntas: ¿en qué grado se han cumplido los objetivos y criterios establecidos?, ¿qué factores de los estudiantes han favorecido o dificultado el aprendizaje?, ¿qué elementos de la metodología de enseñanza (considerar estrategias, técnicas, recursos, actitudes personales, rasgos institucionales, etc.) han funcionado satisfactoriamente y cuáles de ellos pudieran mejorarse?, ¿la estrategia de evaluación es realmente un insumo para comprender el aprendizaje en mi aula?

5. Establecer un plan de acción: luego de la reflexión realizada, no sólo como un acto subjetivo, sino mediante los resultados que los estudiantes han expresado, es posible tomar decisiones sobre aquello que puede mejorarse en el aula.

\section{Conclusiones}

La evaluación en general ejercida como un hábito, se muestra como un proceso estándar; sin embargo, es flexible a las múltiples dimensiones que puede tener el conocimiento y el aprendizaje escolar en la amplitud del término.

La adecuada planeación y ejecución de este proceso provee evidencias que fungen como insumo para la docencia. Manteniendo esta percepción, comenzará a perderse el temor a este proceso como una acción inquisidora, convirtiéndose en una muestra del logro de aprendizajes, de la pertinencia metodológica y de los beneficios de las interacciones desarrolladas por los actores educativos.

\section{Fuentes de consulta}

Díaz B., F. (2006). Enseñanza situada: vínculo entre la escuela y la vida. México: McGraw Hill.

López F. B., Hinojosa K. E. (2001). Evaluación del aprendizaje, alternativas y nuevos desarrollos. México: Trillas.

Martínez R., F. (2012). La evaluación en el aula: promesas y desafios de la evaluación formativa. México: Universidad Autónoma de Aguascalientes. 